\title{
SPATIAL RELATIONSHIPS BETWEEN MOBILITY OPPORTUNITIES AND CONSTRAINTS OF TRANSPORT DISADVANTAGES: THE CASE OF SANTIAGO DE CALI, COLOMBIA
}

\author{
ALEJANDRO L. GRINDLAY ${ }^{1}$, CIRO JARAMILLO² \& CARMEN LIZÁRRAGA ${ }^{3}$ \\ ${ }^{1}$ Department of Urban and Regional Planning, University of Granada, Spain \\ ${ }^{2}$ School of Civil Engineering and Geomatics, University of Valle, Colombia \\ ${ }^{3}$ Department of Applied Economics, University of Granada, Spain
}

\begin{abstract}
The objective of this paper is to explore the spatial distribution of the mobility opportunities linked to the access of the population to the public transport system and its transport disadvantages constraints in relation to socio-economic variables of the districts and estimated local public transport needs. It focuses on the third most populated urban area in Colombia, the metropolitan area of Santiago de Cali. The analysis uses and correlates two spatialized indexes. The index of social transport needs and the index of public transport provision are calculated, both in absolute and relative terms. A statistical analysis has been made, and a spatial analysis of distribution in term of standard deviation. Both indexes were contrasted in absolute and relative terms, and they were spatially studied in a cartography that showed the balance between supply and need in each zone. Lastly, correlation coefficients such as Pearson and Spearman were calculated along with levels of significance to validate the results. The results revealed that distribution of the indexes, the absolute transport social needs and the relative public transport provision, presents a normal distribution, in contrast to the other two indicators. Regarding the standard deviation maps, the distribution of the values below the average is shown to be the majority in the case of the relative index of public transport provision on the periphery of the study area. On the other hand, the spatial distribution of the absolute and relative index of transport social needs in the central areas is below or at the average of the study area. It can be concluded that the opportunities for access to the public transport system are relatively less concentrated in disadvantaged districts with low socio-economic levels.
\end{abstract}

Keywords: public transport provision, mobility opportunities, transport disadvantages, transport social needs, Santiago de Cali, Colombia.

\section{INTRODUCTION}

Considering the relationship existing between mobility, accessibility and social exclusion, a lack of access and mobility is usually a factor of social exclusion which shows itself to a great extent in peripheral groups with restricted access to opportunities that do not allow them to break out of the vicious cycle of poverty, as has been shown in several locations. Hence it is relevant to show the imbalances between the needs for transport and its provision in a public transport system, mainly when it has been improved with rapid transit systems, as has been shown in a previous work, where these gaps are empirically identified in the cartography (Jaramillo et al. [1]). These differences have been proved subsequently in other places, not only in Latin-American cities but also all over the world [2]-[5].

The objective of this paper is to explore the spatial distribution, in an urban context, of the mobility opportunities linked to the access of the population to the public transport system and its transport disadvantages constraints in relation to socio-economic variables of the districts and estimated local public transport needs, and expanding into the spatial and statistical analysis. It also focuses on the third most populated urban area in Colombia, after Bogota and Medellin, the metropolitan area of Santiago de Cali [6]. 
A new public transport system was implemented there in 2009 to solve the serious problems of chaos and insecurity. This new BRT system, called Masivo Integrado de Occidente (MIO) transformed the traditional and generally informal system to a new one, characterized by main line corridors fed by branch lines, with segregated and preferential lanes designated for the exclusive use of buses of high and medium capacity. The public transport system totally transformed the existing one (from 30 operators companies to 5; from 234 routes to 81 ; from 10,235 km route length to $909 \mathrm{~km}$; from $44 \mathrm{~km}$ average route length to $14 \mathrm{~km}$; from $1,000,000 \mathrm{~km}$ a day to $182,000 \mathrm{~km}$; from 4289 vehicles to 937 ), and led to a great improvement in the quality of service [1]. Later studies of this system have shown that, despite the progress in the public transport services, there is still room for improvements, i.e. "thus while MIO has reached very good levels of spatial coverage, the frequency of buses in low-income areas, especially in Stratum 1, is considerably lower" [7].

In view of this need for improvements, it is necessary to go deeper into the analysis of this system, which is why the methodology, results and conclusions of this study are now presented.

\section{METHODOLOGY}

In order to evaluate the spatial distribution of the mobility opportunities linked to the access of the population to the public transport system and its transport disadvantages constraints in relation to socio-economic variables of the districts and estimated local public transport needs, in the previous study two spatialized indexes were defined and calculated, and now are correlated: the index of transport social needs and the index of public transport provision, both in absolute and relative terms with regard the population of each district. In the Index of Transport Social Needs (ITSN), associated with transport disadvantage for each of Santiago de Cali's districts, several factors of transport disadvantage and indicators were considered. There are 22 districts which are classified by six socio-economic strata fixed and adopted by the Colombian National Department of Planning. The least privileged at the bottom of the socio-economic stratification are situated in the peripheral zones which, besides having the handicap of being the greatest distance from the central area, also have a transport infrastructure with the worst conditions, not only for the deficiencies in the state of the road surfaces and drainage, but also for the inadequate road width and very steep slopes (more than 20\%) (Fig. 1). The Index of Public Transport Provision (IPTP) was aimed to develop a comparable measure representative of the level of public transport supply available in each district. Their formulation and calculus are detailed at [1].

In order to evaluate their results in depth, a statistical analysis and a spatial analysis of their distribution in term of standard deviation have been made. Starting from these previous results, an Exploratory Spatial Data Analysis (ESDA) has been carried out, a tool that allows an initial study to be performed prior to more complex statistical procedures [8]. The purpose has been to have structural information on the univariate and bivariate behaviour of the indicators founded. For this purpose, the matrix of data of the normalized indicators, between minimum and maximum corresponding to the studied districts, will be considered. At the univariate level, the measures of central tendency will be determined, as arithmetic mean and median and the dispersion measures as Standard deviation, asymmetry and kurtosis [9].

On the other hand, the possible normal distribution of the variables has been evaluated through the Shapiro-Wilk test, used for a group smaller than fifty (50) units [10]. 


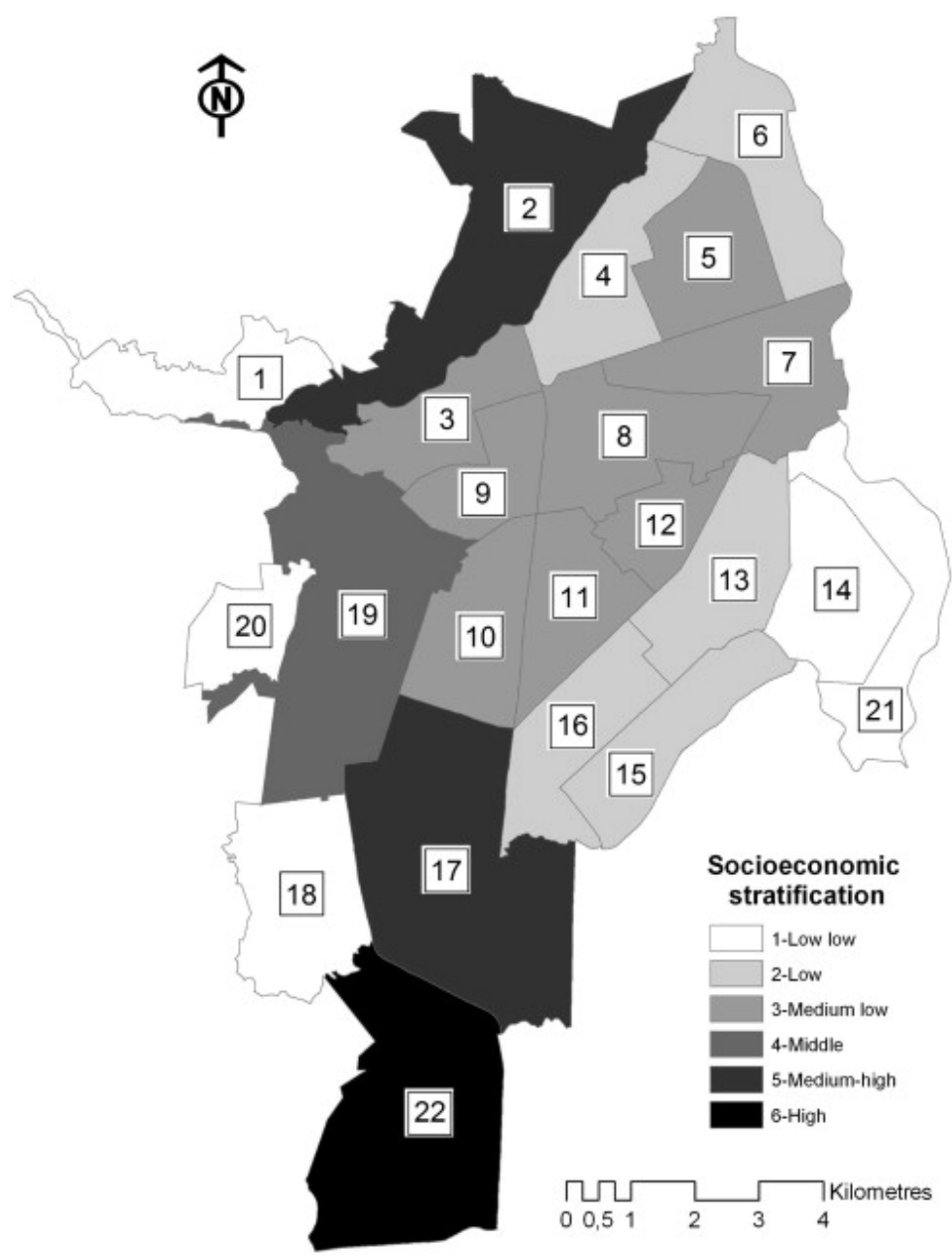

Figure 1: Spatial distribution of the socio-economic strata by district in Santiago de Cali. (Source: Jaramillo et al., 2012.)

With the aim of representing the already normalized indicators, between minimum and maximum, the score is transformed to z-score represented, these new values being the deviation of the index value from the mean. This form of cartographic representation is now perfectly comparable for the different calculated indicators [9]. The expression used is the following:

where:

$$
z-\text { score }=\frac{x_{i}-\mu}{\sigma}
$$

z-score: Standard indicator

$x_{i}$ : Value of the variable in a district $i$

$\mu$ : Average of the variable

$\sigma:$ Standard deviation of the variable 
With the support of the box charts, extreme values are highlighted as a useful representation of the exploratory analysis of spatial data, so a value is considered anomalous when it exceeds at 1.5 the interquartile range formed by the difference between the values that occupy the position of $25 \%$ to $75 \%$ respectively.

At the bivariate level it has been based on comparative processes of the behaviour of the variables, a technique that is based on the scatter diagrams from which the clouds of points formed by the values of the indicators for each district show an approximation to the meaning and intensity of the existing relationship. In addition to these techniques of interactive use, cross-linking graphs generated by the numerical alpha database with digital cartography, these relationships are spatially illustrated. In the scatter diagrams constructed with z-score values, each of the axes takes the central sector of the graph and four (4) basic quadrants are defined in the space of relationships (Fig. 2) The positive $(+)$ and negative $(-)$ values correspond to positions above and below the respective variable [9], [11], [12]. When calculating the regression line based on the cloud of points, and observing the quadrants in which its trajectory is traced, between the quadrants I and III the relation is positive and if its trajectory is between the quadrants II and IV it is negative. The Pearson and Spearman Rho correlation coefficients are used to validate the relationship between the variables being their normal distributions or not. With regard to the assessment of significance in both cases the null-Ho hypothesis is that the spatial configuration occurs randomly.

\section{RESULTS}

The basic data of this analysis are the results of the previously proposed and calculated indexes of transport social needs and public transport provision for each district, both in absolute and relative terms, as it has been mentioned in Table 1. The results of the later statistical analysis are shown in Table 2.

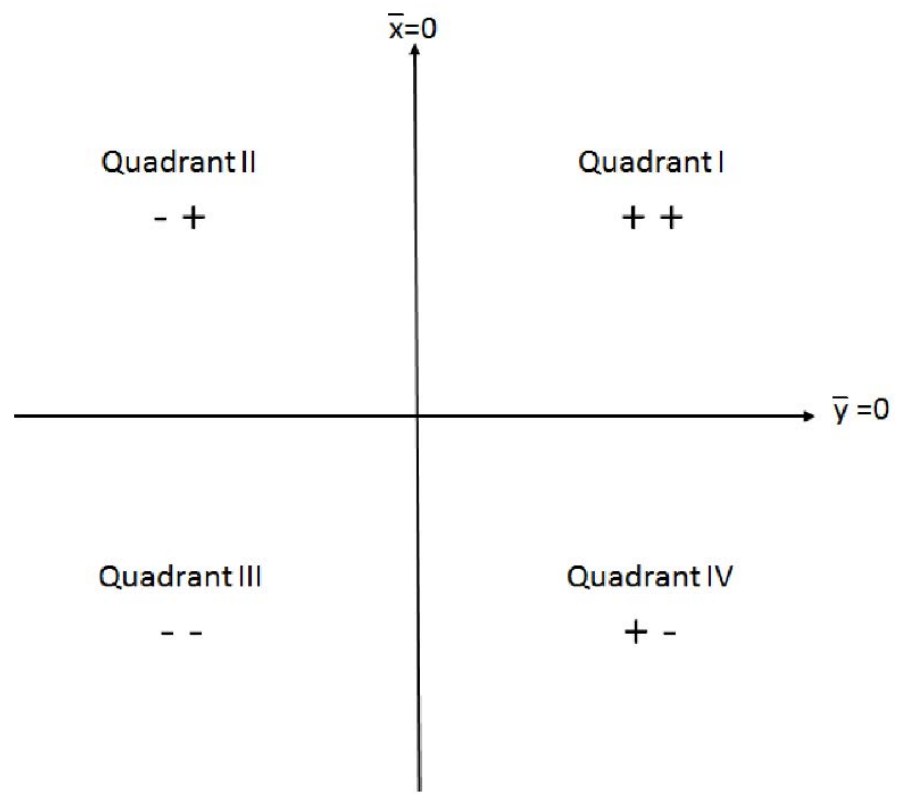

Figure 2: Quadrants of bivariate relationships between variables with z-score. 
Table 1: Values of ITSN and IPTP indexes in absolute and relative terms for each district. (Source: Jaramillo et al., 2012.)

\begin{tabular}{|c|c|c|c|c|}
\hline \multirow{2}{*}{$\begin{array}{l}\text { District } \\
\text { number }\end{array}$} & \multicolumn{4}{|l|}{ Indexes } \\
\hline & ITSN_A & ITSN_R & IPTP_A & IPTP_R \\
\hline 1 & 35.8 & 100.00 & 0.00 & 0.00 \\
\hline 2 & 38.2 & 26.5 & 51.14 & 25.71 \\
\hline 3 & 18.03 & 59.81 & 89.18 & 100.00 \\
\hline 4 & 24.53 & 54.44 & 58.51 & 51.75 \\
\hline 5 & 41.18 & 38.72 & 61.47 & 30.27 \\
\hline 6 & 92.5 & 82.37 & 56.73 & 16.43 \\
\hline 7 & 36.6 & 65.91 & 69.31 & 46.14 \\
\hline 8 & 39.09 & 40.66 & 56.24 & 28.21 \\
\hline 9 & 19.99 & 55.79 & 83.52 & 85.5 \\
\hline 10 & 38.87 & 32.86 & 100.00 & 47.51 \\
\hline 11 & 45.81 & 56.57 & 93.79 & 46.92 \\
\hline 12 & 30.67 & 62.98 & 32.72 & 24.23 \\
\hline 13 & 100.00 & 90.12 & 36.36 & 10.31 \\
\hline 14 & 93.81 & 95.42 & 55.32 & 17.55 \\
\hline 15 & 72.57 & 90.36 & 41.72 & 16.26 \\
\hline 16 & 43.07 & 59.67 & 53.85 & 28.02 \\
\hline 17 & 41.23 & 24.18 & 45.69 & 21.43 \\
\hline 18 & 48.72 & 69.6 & 25.53 & 13.02 \\
\hline 19 & 41.88 & 29.14 & 57.25 & 28.12 \\
\hline 20 & 35.68 & 86.96 & 16.45 & 12.59 \\
\hline 21 & 51.93 & 93.16 & 55.55 & 31.63 \\
\hline 22 & 0.00 & 0.00 & 13.02 & 82.58 \\
\hline
\end{tabular}

Table 2: Descriptive statistics of the ITSN and IPTP indexes $\left({ }^{*} \mathrm{Ho}\right.$ is accepted, normal distribution).

\begin{tabular}{|l|l|l|l|l|}
\hline \multirow{2}{*}{ Statistical } & \multicolumn{4}{l|}{ Indexes } \\
\cline { 2 - 5 } & ITSN_A & ITSN_R & IPTP_A & IPTP_R \\
\hline Average & 45.0073 & 59.7827 & 52.4250 & 34.7355 \\
(Typical error) & $(5.28242)$ & $(5.83447)$ & $(5.48501)$ & $(5.52907)$ \\
\hline Median & 40.1350 & 59.7400 & 55.4350 & 28.0700 \\
\hline Typical deviation & 24.77673 & 27.36609 & 25.72697 & 25.93362 \\
\hline Asymmetry & 0.930 & -0.316 & -0.063 & 1.286 \\
(Typical error) & $(0.491)$ & $(0.491)$ & $(0.491)$ & $(0.491)$ \\
\hline Kurtosis & 0.852 & -0.615 & -0.110 & 1.119 \\
(Typical error) & $(0.953)$ & $(0.953)$ & $(0.953)$ & $(0.953)$ \\
\hline Shapiro-Wilk test & 0.878 & $0.955^{*}$ & $0.967^{*}$ & 0.864 \\
\hline (Significance) & $(0.011)$ & $(0.398)$ & $(0.632)$ & $(0.006)$ \\
\hline
\end{tabular}


When reviewing in Table 2 the measures of central tendency, such as the average, it can be seen that of the four indicators the IPTP_R presents the lowest value based on the transport provision and the highest value of transport need is the ITSN_R, in both cases the most relevant indicators were those related to the area and population. Regarding the behaviour of the median it is analogous to the mean but with higher values. When comparing these two statistics, the proximity between them is more noticeable in the case of ITSN_R and IPTP_A, which reflects a distribution closer to the symmetry. As far as the standard deviation is concerned, the values for the calculated indicators are similar indicating a behaviour of the distributions, in contrast to the average, similar. The asymmetry of the ITSN_R and IPTP_A is located to the right of the centre of the histogram but close to it. On the other hand the ITSN_A and IPTP_R are oriented to the left. As for the kurtosis distribution ITSN_R and IPTP_A is flatter and for ITSN_A IPTP_R is more protuberant. The Shapiro-Wilk test proposes, as null-Ho hypothesis, that the distribution of the data follows a normal distribution, as it seemed in the value of the statistic, for ITSN_R and IPTP_A the $\rho$-value $>0.05$, therefore these two indicators do not reject the Ho, i.e. they have normal distribution, contrary to what is appreciated with the indicators ITSN_A and IPTP_R.

Consequently, the results revealed that distribution of the indexes, the relative transport social needs and the absolute public transport provision, presents a normal distribution, in contrast to the other two indicators.

These indicators have also been mapped with respect to their standard deviation (Fig. 3) and it is shown that the distribution of the values below the average is the majority in the case of the relative index of public transport provision on the periphery of the study area where the low-income districts are.

Fig. 3 shows low ITSN_A values in two (2) districts in the centre of the city and one (1) district in the south zone, high values in two (2) districts in the central-east zone and one (1) district in the north-east, in the central area the IPTP_A is above the average in four (4) districts and there are deficient values in four (4) districts in the western part of the city, the rest of the city is about average in both cases. The ITSN_R representation identifies a (1) district in the centre of the west and four (4) districts in the centre-east with high values, a north-south belt is identified with four (4) districts with values per below average. When analyzing the distribution of the IPTP_R, two (2) districts can be seen in the centre and one (1) district in the south with high values and in the central west zone one (1) district with low values and the rest of the city has values close to the average. Generally the spatial distribution of the absolute and relative index of transport social needs in the central areas is below or at the average of the study area

The results have also revealed the extreme values shown by the atypical districts according to indicators IPTP_A, IPTP_R and ITSN_A (Fig. 4). In the IPTP_A an extreme value was found in the centre of the city, in the IPTP_R the high anomalous point is in the centre also coinciding with the Central Business District or CBD. The ITSN_A has an atypical value with low value in the southern part, which is the highest income in the city; the high atypical values are located in the east towards the centre and the north districts where the rent are the lowest in the city.

In addition, a correlation analysis has been made to validate the results. Table 3 shows the values of the correlation coefficients given for the relationship between provision and social transportation needs indicators. It is shown that the correlations of ITSN_A and ITSN_R with IPTP_R all have a $\rho$-value $<0.05$ which allows the Ho to be rejected and to accept that the spatial configuration does not occur in a random way, in all the mentioned cases the correlation coefficients are negative, i.e. the regression line is in quadrants II and IV. Then 
the alphanumeric data are linked to the associated mapping representation, which allows different representations to be made from the partial selections in the scatter plot.

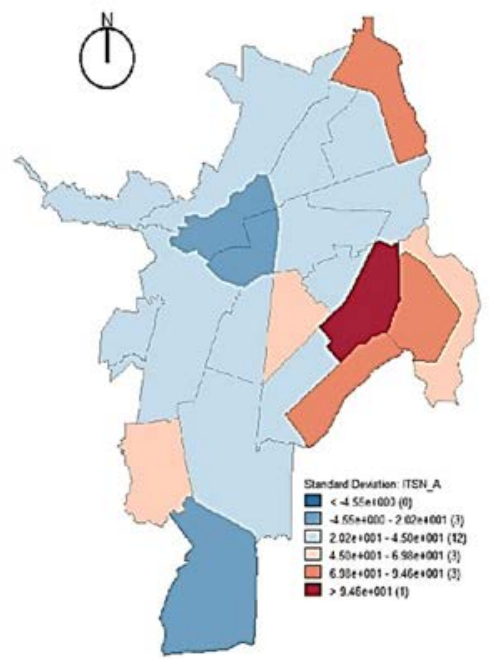

(a) ITSN A

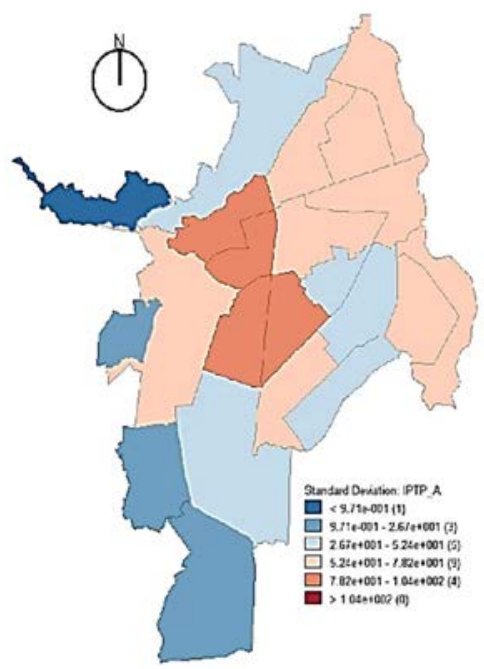

(c) IPTP A

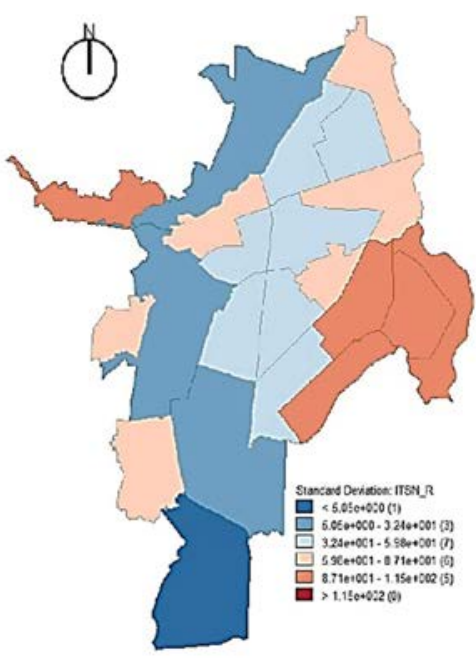

(b) ITSN R

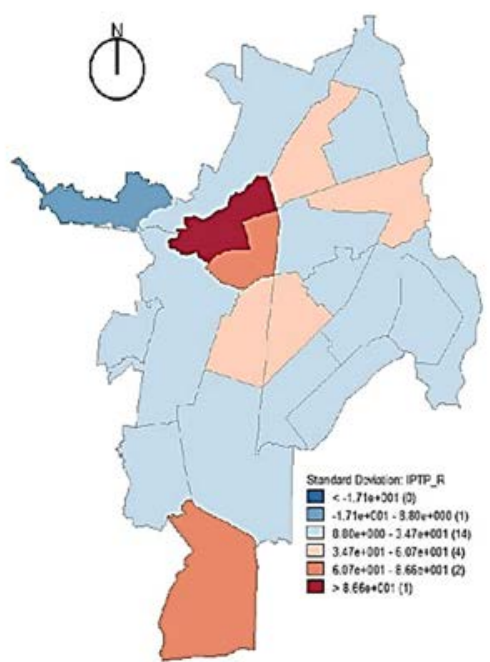

(d) IPTP R

Figure 3: Standard deviation maps of the IPTP and ITSN indicators. 


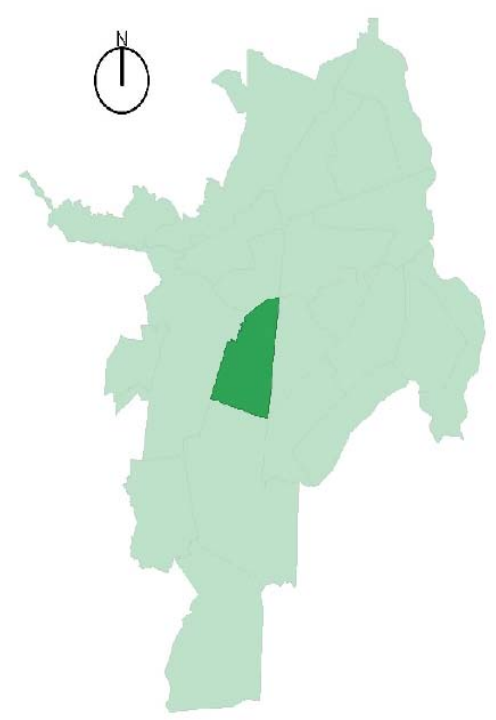

(a) Atypical district for IPTP A

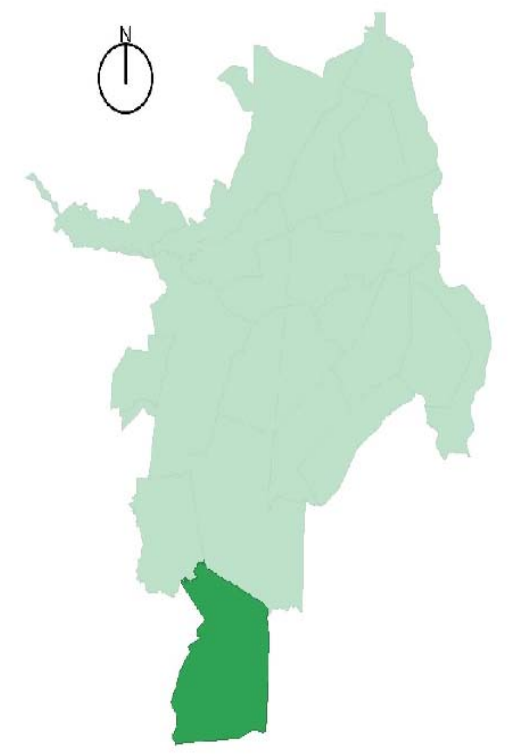

(c)

Atypical district for ITSN A (low)

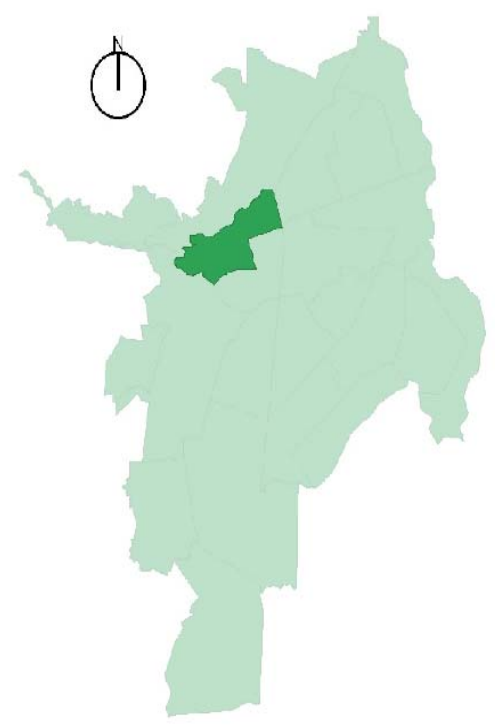

(b) Atypical district for IPTP R

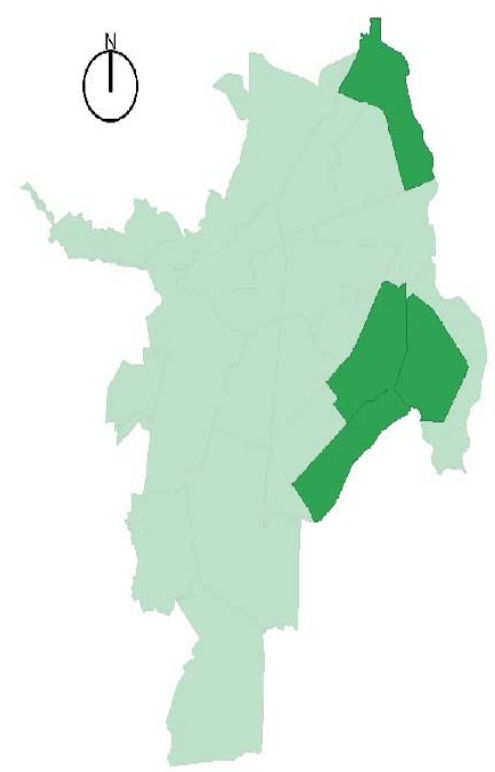

(d) Atypical districts for ITSN A (high)

Figure 4: Location of atypical districts for IPTP and ITSN indicators. 


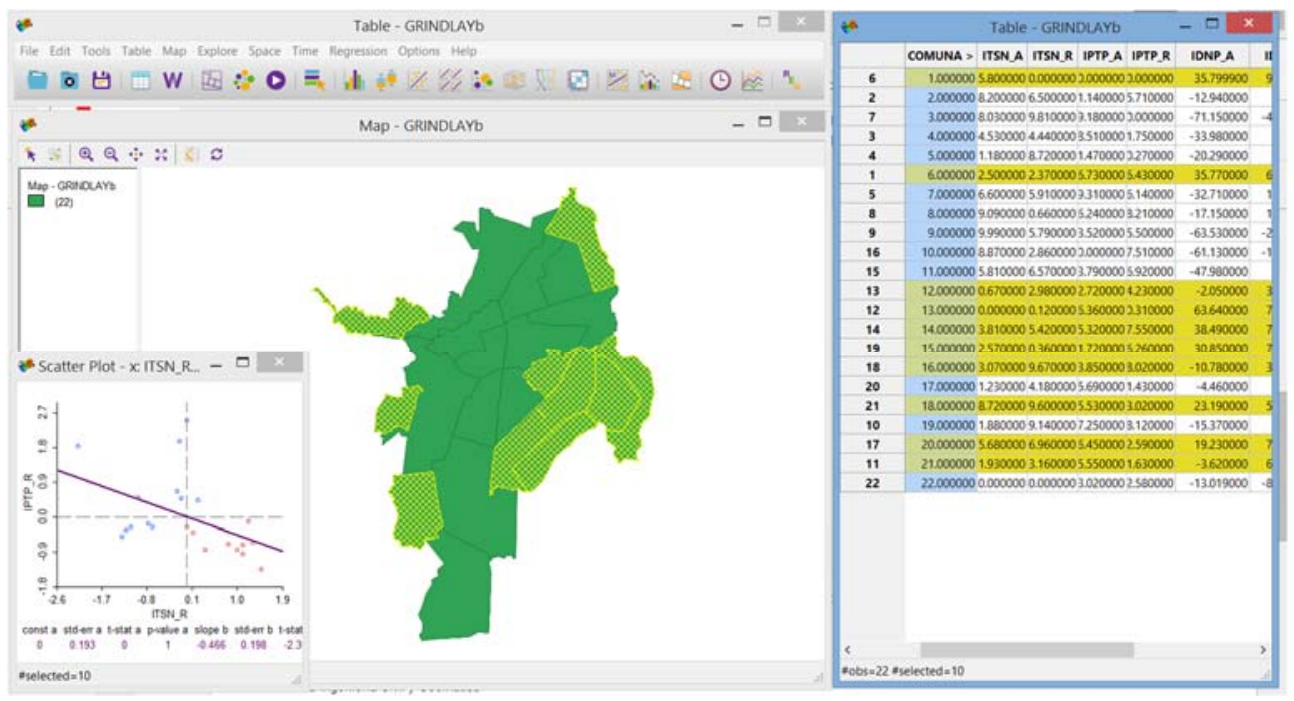

Figure 5: Correlation results depicted cartographically.

According to these correlation results the atypical districts have been depicted cartographically, which is shown in the next figures (Fig. 5; Fig. 6).

Indicating the districts with high values of ITSN_A and low IPTP_R located in quadrant II, as Fig. 4(a) shows, there are five (5) districts located in the east area of the city and one (1) district in the south-western zone. In contrast, the districts with low values of ITSN_A and high values of IPTP_R of quadrant IV, in Fig. 4(b), are evident in one (1) district in the south and one strip of six (6) centre districts to the north-east zone. On the other hand, Fig. 4(c) shows behaviours in quadrant II with high values for ITSN_R and low values for IPTP_R located in three (3) districts in the west and one (1) district in the north-east zone and six (6) districts in the central east zone. Lastly Fig. 4(d) in quadrant IV shows low values of ITSN_R and high values of IPTP_R which are located in one (1) district in the south area and five (5) districts in a strip located from the centre towards the north east.

\section{DISCUSSION AND CONCLUSION}

This work has deepened the analytical potential of the proposed indicators [1]. Despite the significant qualitative leap that led to the implementation of the BRT system known as MIO in the city of Santiago de Cali, some general improvements in the public transport system still need to be made, as can be seen in another study [7], and in this new analysis the most problematic districts that need particular attention are clearly shown.

In addition, the results of the statistical analysis have revealed that distribution of the indexes, the relative transport social needs and the absolute public transport provision, presents a normal distribution, in contrast to the other two indicators.

The relationship between indicators, whose results are validated with the significant correlation coefficients obtained, show the utility of the spatial analysis carried out which allows the problems of the system to be shown more clearly and related improvements to be proposed. 


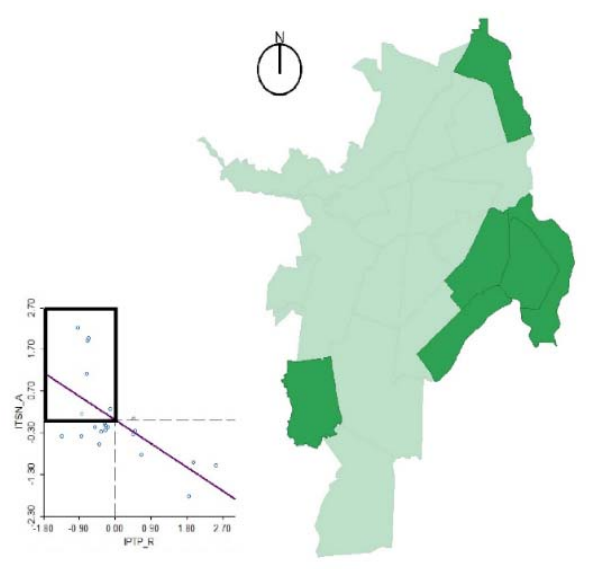

(a) Association IPTP R vs. ITSN A-II quadrant

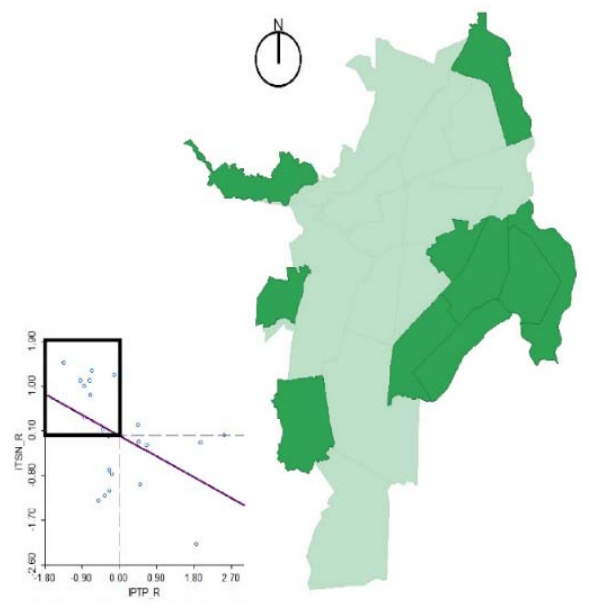

(c) Association IPTP R vs. ITSN R-II quadrant

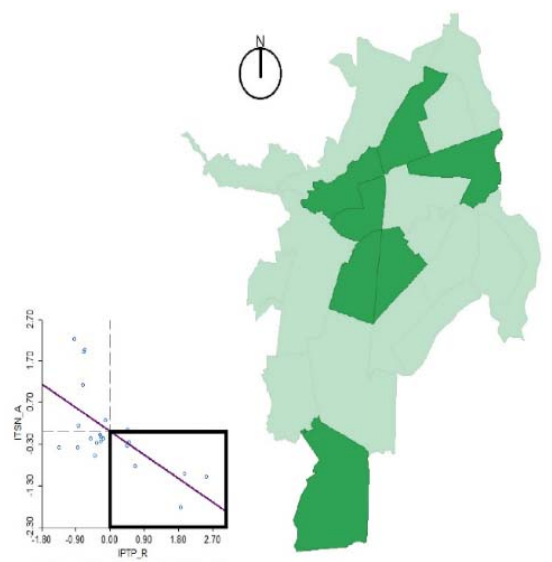

(b) Association IPTP R vs. ITSN A-IV quadrant

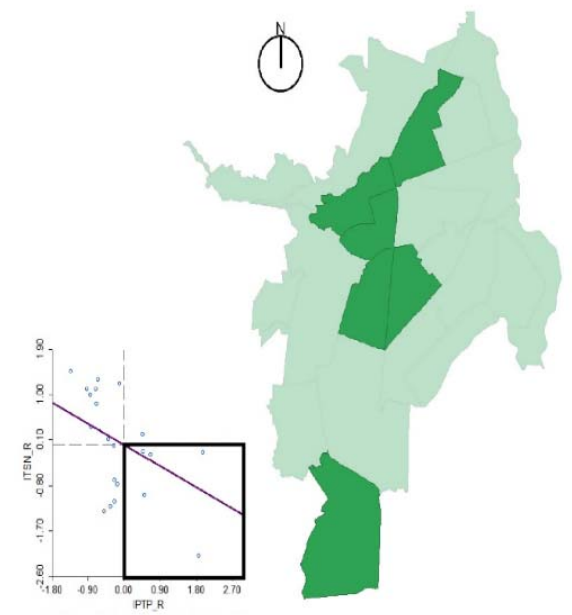

(d) Association IPTP R vs. ITSN R-IV quadrant

Figure 6: Location of atypical districts for IPTP and ITSN indicators.

This constitutes a useful representation of an exploratory analysis of spatial data, indicating the anomalous districts considered.

Particularly the less privileged districts are clearly indicated by the relationship of the absolute index of transport social need (ITSN_A) and relative index of public transport provision (IPTP_R) with high values of the first and low values of the second index respectively. This fact is even more evident from the relationship of the relative index of transport social need (ITSN_R) and relative index of public transport provision (IPTP_R) highlighting those districts with high values of the first and low values of the second index respectively. On the other hand, through the relationship of the absolute index of transport social need (ITSN_A) and relative index of public transport provision (IPTP_R), the 
wealthiest districts are indicated, with low values of the first and high values of the second index. These are conspicuous when considering the relationship of the relative index of transport social need (ITSN_R) and relative index of public transport provision (IPTP_R).

Finally, it can be concluded, as is usually the case, that the opportunities for access to the public transport system are relatively less concentrated in disadvantaged districts with low socio-economic levels of peripheral areas.

\section{REFERENCES}

[1] Jaramillo, C., Lizárraga, C. \& Grindlay, A.L., Spatial disparity in transport social needs and public transport provision in Santiago de Cali (Colombia). Journal of Transport Geography, 24, pp. 340-357, 2012.

[2] Venter, C., Hildalgo, D. \& Pineda, A., Assessing the equity impacts of bus rapid transit: emerging frameworks and evidence. Presented at $13^{\text {th }}$ World Conference on Transportation Research, Rio de Janeiro, Brazil, 2013.

[3] Fransen, K., Neutens, T., Farber, S., De Maeyer, P., Deruyter, G. \& Witlox, F., Identifying public transport gaps using time-dependent accessibility levels. Journal of Transport Geography, 48, pp. 176-187, 2015.

[4] Lucas, K., Mattioli, G., Verlinghieri, E. \& Guzman, A., Transport poverty and its adverse social consequences. Proceedings of the Institution of Civil Engineers-Transport, ICE Publishing, 169(6), pp. 353-365, 2016.

[5] Lucas, K., Bates, J., Moore, J. \& Carrasco, J.A., Modelling the relationship between travel behaviours and social disadvantage. Transportation Research Part A: Policy and Practice, 85, pp. 157-173, 2016.

[6] Montoya Garay, J.W., El sistema urbano colombiano frente a la globalización: reestructuración económica y cambio regional. Cuadernos de Vivienda y Urbanismo, 6(12), pp. 302-320, 2013.

[7] Scholl, L., Bouillon, C.P., Oviedo, D., Corsetto, L. \& Jansson, M., Urban Transport and Poverty: Mobility and Accessibility Effects of IDB-supported BRT Systems in Cali and Lima, Inter-American Development Bank: Washington, 2016.

[8] Anselin, L., Interactive techniques and exploratory spatial data analysis. Geographical Information Systems: Principles, Techniques, Management and Applications, eds. P. Longley, M. Goodchild, D. Maguire \& D. Rhind, Geoinformation Int: Cambridge, pp. 253-266, 1999.

[9] Anselin, L., Exploring Spatial Data with Geodatm: A Workbook. Center for Spatially Integrated Social Science: Urbana, 2004.

[10] Shapiro, S.S. \& Wilk, M.B., An analysis of variance test for normality (complete samples). Biometrika, 52(3-4), pp. 591-611, 1965.

[11] Bosque Sendra, J. \& Zamora Ludovic, H., Visualización Geográfica y nuevas Cartografías. GeoFocus Rev. Int. Cienc. Tecnol. Inf. Geográfica, 2, pp. 61-77, 2002.

[12] Buzai, G.D. \& Baxendale, C.A., Análisis Socioespacial Con Sistemas de Información Geográfica. Gepama: Buenos Aires, 2011. 